PPPL-3172 - Preprint Datê: May 1996, UC-420, 424, 426

\title{
Measurements of tritium retention and removal on TFTR.
}

C H Skinner, W Blanchard, J Kamperschroer, P LaMarche, D Mueller, A Nagy, S Scott, G Ascione, E Amarescu, R Camp, M Casey, J Collins, M Cropper, C Gentile, M Gibson, J Hosea, M Kalish, J Langford, S Langish, R Mika, D K Owens, G Pearson, S Raftopoulos, R Raucci, T Stevenson, [ $A$ Von Halle, $D$ Voorhees, $T$ Walters, $J$ Winston. Mry 28 कis

Princeton University, Plasma Physics Laboratory 037 Princeton, NJ, 08543

\begin{abstract}
Recent experiments on the Tokamak Fusion Test Reactor (TFTR) have afforded an opportunity to measure the retention of tritium in a graphite limiter that is subject to erosion, codeposition and high neutron flux. The tritium was injected by both gas puff and neutral beams. The isotopic mix of hydrogenic recycling was measured spectroscopically and the tritium fraction $\mathrm{T} /(\mathrm{H}+\mathrm{D}+\mathrm{T})$ increased to as high as $75 \%$. Some tritium was pumped out during the experimental run and some removed in a subsequent campaign using various clean-up techniques. While the short term retention of tritium was high, various conditioning techniques were successful in removing $\approx 8,000 \mathrm{Ci}$ and restoring the tritium inventory to a level well below the administrative limit.
\end{abstract}

\section{Introduction}

Graphite is one of the primary candidate materials for first wall components in fusion devices due to its high sublimation point and the low radiative power losses of carbon impurities in a high temperature plasma. An important design issue is the trapping of hydrogen isotopes in graphite which could raise the in-vessel tritium inventory to unacceptable levels unless an effective removal technique is implemented. TFTR has a special opportunity to study the issues involved since it has a graphite limiter which experiences erosion, codeposition and neutron flux from DT plasmas with core fusion power similar to that expected for ITER. Below $1000^{\circ} \mathrm{C}$, 
retention in graphite is characterized by saturation of the near surface region and by surface diffusion on internal porosity. ${ }^{1-3}$ A study of deuterium retention, based both on modeling and measurements on graphite tiles and wall coupons removed from TFTR, was reported in reference 4. The overall fractional retention of deuterium in TFTR was found to be $45 \%$. Of this, $22 \%$ was on the plasma facing surface of the bumper limiter, $9 \%$ on the sides of the gaps between the limiter tiles and $14 \%$ on the vacuum vessel wall. Comparison of different run periods showed that the retention varied in the range $22 \%-63 \%$ and this variation was correlated with the average neutral beam power. This pattern was attributed to increased edge and limiter temperatures leading to more codeposition at high beam powers. A stronger plasma-limiter interaction at high powers is also indicated by the higher level of CII $658 \mathrm{~nm}$ emission. The fate of trace tritium produced in DD nuclear reactions was also studied. Tile analysis 5 indicated that $\approx 35 \%$ of the tritium produced was retained in the internal components of TFTR.

Retention issues have also been studied on JET. During the preliminary tritium experiment, 54 $\mathrm{Ci}$ of tritium were injected into the vessel in two discharges. Following this, a series of experiments were performed to remove tritium and study the efficacy of the different cleaning procedures. ${ }^{6}$ High density disruptive discharges were found to be the most successful plasmas for tritium removal. A simple 'soak' with deuterium gas was also effective, however, helium discharges resulted in low tritium release from the vessel walls. A recent appraisal of deuterium retention in $\mathrm{JET}^{7}$ indicated that $40 \%$ of the gas input remains in the vessel at the end of the day.

In section 2 we describe the TFTR vacuum vessel and neutral beam systems and, in section 3 , tritium operations. Recently, tritium gas puffing was used to generate L- mode plasmas for transport and RF experiments and the corresponding increase in the tritium inventory of the limiter is described in section 4. Section 5 describes the subsequent campaign to remove tritium and ascertain the amount of remaining tritium that was tenaciously held and would not be released in the event of a credible vacuum accident. A summary discussing TFTR, JET and future DT machines concludes the paper.

\section{Experiments on TFTR}

Since 1993, TFTR has been operated routinely with deuterium-tritium plasmas. Fusion powers up to $10.7 \mathrm{MW}$ have been obtained in 'supershot' plasmas heated by high power tritium and deuterium neutral beam injection. ${ }^{8}$ At these levels, the fusion power density in the core, $\sim 2 \mathrm{MW} / \mathrm{m}^{3}$ as well as many alpha parameters are comparable to those expected for the core of future ignition machines such as ITER. TFTR plasmas have a circular cross section of minor radius typically in the range $0.8-0.96 \mathrm{~m}$ and a major radius $2.45-2.62 \mathrm{~m}$. The plasma boundary 
is defined by an inner toroidal belt limiter composed of carbon composite tiles in high heat flux regions as well as graphite tiles, both supported by water cooled inconel- 718 backing plates. The limiter extends over $\pm 60^{\circ}$ from the midplane and is divided into 20 sectors, each composed of 24 rows of tiles, four tiles wide, with each tile covering about $4.5^{\circ}$ toroidally and $5^{\circ}$ poloidally. Each sector is curved and the center extends out about $5 \mathrm{~mm}$ from a true toroidal surface. The total area of the limiter is $22 \mathrm{~m}^{2}$ of which approximately $7 \mathrm{~m}^{2}$ contacts the plasma. The limiter experiences erosion, codeposition and neutron flux from the DT plasmas. After exposure to many plasma discharges each limiter sector develops a poloidally asymmetric 'footprint' or eroded area, surrounded by areas of net codeposition..$^{9}$ The pattern is related to the angle of the incident flux on the individual tiles and the slight toroidal asymmetry of the limiter. ${ }^{10}$ The rise in bulk limiter temperature remains below $50^{\circ} \mathrm{C}$ during a discharge, ${ }^{11}$ however infra-red camera measurements indicate that the surface temperature in localized hot spots increase up to $1000^{\circ} \mathrm{C}$ or more depending on the discharge conditions and auxiliary heating power. ${ }^{12}$

The neutral beam system comprises four neutral beam lines each having three beam sources that can independently operate in either deuterium or tritium in a given discharge. The fueling rate of the neutral beams is computed from the extracted ion current, the neutralization efficiencies ${ }^{13}$ of the three components of the beam, ${ }^{14}$ and their transport efficiencies through the beamline. The amount of tritium supplied to an ion source for a $1 \mathrm{~s}$ tritium pulse is approximately $250 \mathrm{Ci}$. Of this amount, approximately $4 \%$ is injected into the torus as energetic neutrals. The remainder, including un-neutralized ions initially collected by copper beam dumps, is pumped on liquid helium cryopanels inside the beamlines. Even though the beamlines are differentially pumped, there is a small leakage of cold gas into the torus. This throughput is estimated from the neutral beam drift duct conductance and the tritium pressure in the beamline. The duct conductance for deuterium was found to be $46 \mathrm{~m}^{3} \mathrm{sec}^{-1}$ by measuring the pumping speed of the torus when it was pumped solely by one beamline. A mass correction was applied to yield the tritium conductance. Pressures of $\sim 10^{-6}$ torr are typically developed at the beamline end of the duct when three ions sources are pulsed. Cold gas throughputs of 0.1 torr- $1 / \mathrm{s}$ per ion source are thereby estimated. Cold gas fluence is approximately $6 \%$ of that of the energetic particles.

\section{Tritium operations}

A detailed account of tritium processing and management on TFTR is given in reference 15. Tritium gas is brought on-site in an approved shipping canister and transferred to a uranium bed where it is stored. The uranium bed is heated to transfer the gas to the neutral beams or torus gasinjection system. Tritium is released from calibrated volumes by piezo-electric valves that are actuated for a short time during the discharge. The quantity of tritium injected is measured by 
monitoring the temperature and pressure of the calibrated volume with an experimental uncertainty of $2 \%$. Tritium is injected into the torus by the neutral beam system or puffed in directly. Tritium exhaust is pumped by the liquid helium cooled cryopanels in the beam boxes and/or by turbopumps in the torus vacuum pumping system. After completion of approximately two days of plasma operations, the neutral beam cryopanels are warmed up to a temperature where the hydrogenic species are evaporated. The gas is transferred to one of two $7 \mathrm{~m}^{3}$ gas holding tanks for inventory measurements and subsequently is oxidized and absorbed in molecular sieve beds. These beds are shipped off-site for reprocessing or burial. Recently a tritium purification system was installed that will allow the tritium system to be operated closed loop.

The tritium inventory in the gas holding tanks is measured by parallel plate ion chambers (Femto-Tech) in a sample loop that is maintained at a pressure of 740 torr. These are calibrated in-house by adding a calibrated volume of tritium at a known pressure and temperature to the gas holding tanks. ${ }^{16} \mathrm{~A}$ quadrupole mass spectrometer analyzes the gas content and the ion chamber response is corrected for the differing work functions of impurity gases. The quadrupole mass spectrometer is itself calibrated by measuring the response to various standard gases. In this way the ion chamber response is calibrated over a gas holding tank range from 200 to $11,000 \mathrm{Ci}$. The measurement uncertainty depends on the inventory in the gas holding tanks and is typically in the range $5 \%-7 \%$. Since $96 \%$ of the tritium used by the neutral beams is pumped by the cryopanels without entering the torus, the amount injected into the torus is of the same order as the uncertainty in the measurement of tritium recovered from the cryopanels. Hence there is a relatively high level of uncertainty in the day to day retention of tritium in the torus. This limitation was circumvented for some of the measurements described below by reserving a neutral beam line solely for tritium exhaust measurements.

At the beginning of the DT campaign in TFTR, $360 \mathrm{Ci}$ of tritium was injected into the torus by 21-DT neutral beam heated discharges (most of which used only one tritium beam source) interspersed with $55 \mathrm{DD}$ pulses. Following this, a short clean-up experiment was performed ${ }^{17}$ in which $28 \pm 50 \mathrm{Ci}$ were recovered after a series of 34 deuterium ohmic discharges and deuterium neutral beam injection discharges. Although the measurements had a relatively high level of uncertainty, they indicated a high short-term retention level.

The tritium accounting system in place on TFTR provides a global measure of all tritium supplied to and recovered from the torus and neutral beam systems. By the end of August, 1995, a total of $432,000 \mathrm{Ci}$ had been supplied to the neutral beam systems of which $18,000 \mathrm{Ci}$ entered the torus (the neutral beam fueling is computed as described in section 2 and includes the cold 
gas contribution). In addition, a trace amount $(203 \mathrm{Ci})$ of tritium was puffed directly into the torus in experiments to study transport. Tritium exhaust is collected on the neutral beam cryopanels and also pumped by the torus pumping system. The neutral beam cryopanels are regenerated into gas holding tanks which also collect the effluent from the torus pumping system. The difference between the total tritium delivered to the torus and neutral beam systems and that recovered in the gas holding tanks was approximately 7,000 Ci. Comparing this to estimates of the total tritium injected into the torus by the neutral beam systems yields an estimate of the long term retention of approximately $40 \%$. This value is consistent with the earlier deuterium measurements reported in refs. 4,5 . The administrative limit on the in-vessel inventory is $20,000 \mathrm{Ci}$.

\section{Tritium injection and removal during L-mode experiments.}

In September 1995 experiments were performed in L-mode plasmas on the isotope scaling of Lmode transport ${ }^{18}$ and on RF heating at the tritium 2 nd harmonic cyclotron frequency. ${ }^{19}$ To generate L-mode plasmas, tritium gas was puffed directly into the discharge by the torus gas injection system. In addition, tritium (and deuterium) neutral beam injection was used to heat the plasma. These experiments afforded an opportunity to measure tritium retention with significantly reduced experimental uncertainty. The amount of tritium puffed into the torus by gas injection system in September was $10,600 \mathrm{Ci}$, much higher than the $203 \mathrm{Ci}$ puffed in the earlier tritium transport experiments. Recycling from the limiter increased with the tritium gas injection. The isotopic mix of hydrogenic isotopes recycled from the limiter is measured spectroscopically by measurements of the $\mathrm{H}_{\alpha}, \mathrm{D}_{\alpha}$, and $\mathrm{T}_{\alpha}$ emission lines. ${ }^{20}$ Prior experience with tritium neutral beam injection and trace tritium gas puffs was that the fraction of $\mathrm{T}_{\alpha}$ was low, even with tritium only neutral beam injection. The maximum fraction of $T_{\alpha} /\left(H_{\alpha}+D_{\alpha}+T_{\alpha}\right)$ observed previously was $9 \%$ after 8 discharges heated by tritium only neutral beam injection. ${ }^{21}$ During the L-mode experiments, the quantity of tritium injected into the torus by gas puff was larger than that injected by the neutral beams. With the first tritium puff discharge, the fraction of tritium in the recycled hydrogen isotopes increased from below $3 \%$ up to $22 \%$. However the $\mathrm{T}_{\alpha}$ fraction was slow to change further with subsequent discharges.

Figure 1 shows the $\mathrm{H}_{\alpha}, \mathrm{D}_{\alpha}$, and $\mathrm{T}_{\alpha}$ spectral profile in a discharge with a tritium puff and $\mathrm{RF}$ heating and, for comparison, a similar discharge without tritium injection. The line profiles are Doppler broadened and asymmetric. The maximum $\mathrm{T}_{\alpha}$ fraction reached was $75 \%$ indicating that a longer period is needed for complete exchange of deuterium and tritium in the region of the limiter that is accessed by the plasma. Later in September, these experiments were followed by a conditioning campaign to restore a low limiter recycling state for supershot experiments. ${ }^{22}$ This 


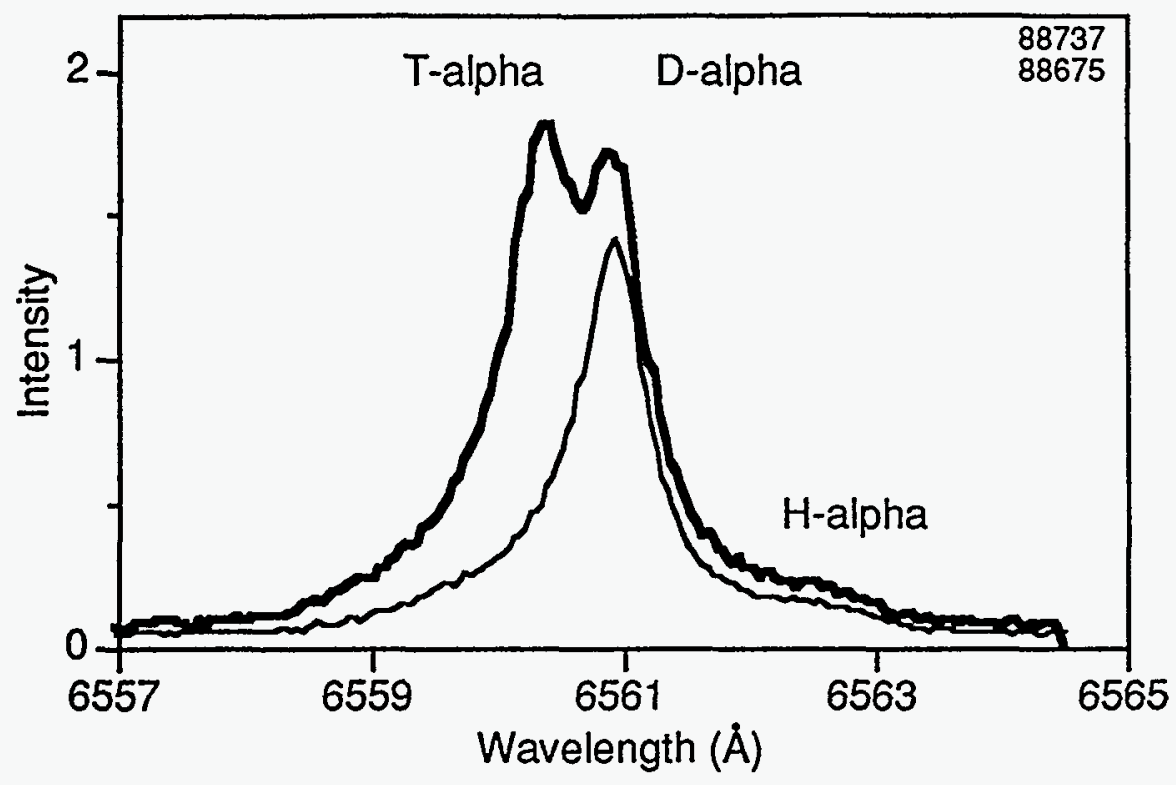

Fig 1. Balmer alpha emission showing the presence of all three hydrogen isotopes. For comparison the spectral profile from an earlier discharge without tritium is shown.

incorporated high power neutral beam heated discharges followed by discharges with lithium pellet injection 23 to reduce the edge influx.

To avoid the difficulty of measuring the tritium exhaust from the torus in the presence of the 25 times higher amount of tritium used by the neutral beams, one of the four neutral beam lines was reserved solely as a pump for the tritium exhaust and had no tritium gas feed. The torus pumping system was closed off and the torus interface valves to the neutral beam boxes left open so that the cryopanels in the four neutral beam boxes pumped the torus. The duct conductances of the four beamlines are identical so that $1 / 4$ of the tritium was pumped by the reserved beamline. The cryopanels were regenerated approximately every second day and a measurement made of the tritium recovered. The total tritium exhaust from the torus was estimated by multiplying that recovered by the reserved beamline by four.

The results are shown in Table I and Fig. 2. In the table, the second column refers to the plasma operations on a particular day in a highly abbreviated way: for example 'DT L-mode' means Lmode experiments using both deuterium and tritium, 'He4 GDC' is glow discharge cleaning using $4 \mathrm{He}$, 'D supershot' is supershot plasma operations with D only, 'PDC' is pulse discharge cleaning. The next 2 columns give the quantity (in curies) of the total tritium injected via gas puff, and neutral beam injection on a particular day. The 'NB vent' refers to tritium recovered from the neutral beam boxes and 'various' refers to miscellaneous pumps and purges over the period 6 October-17th November. The following two columns give the tritium recovered from 


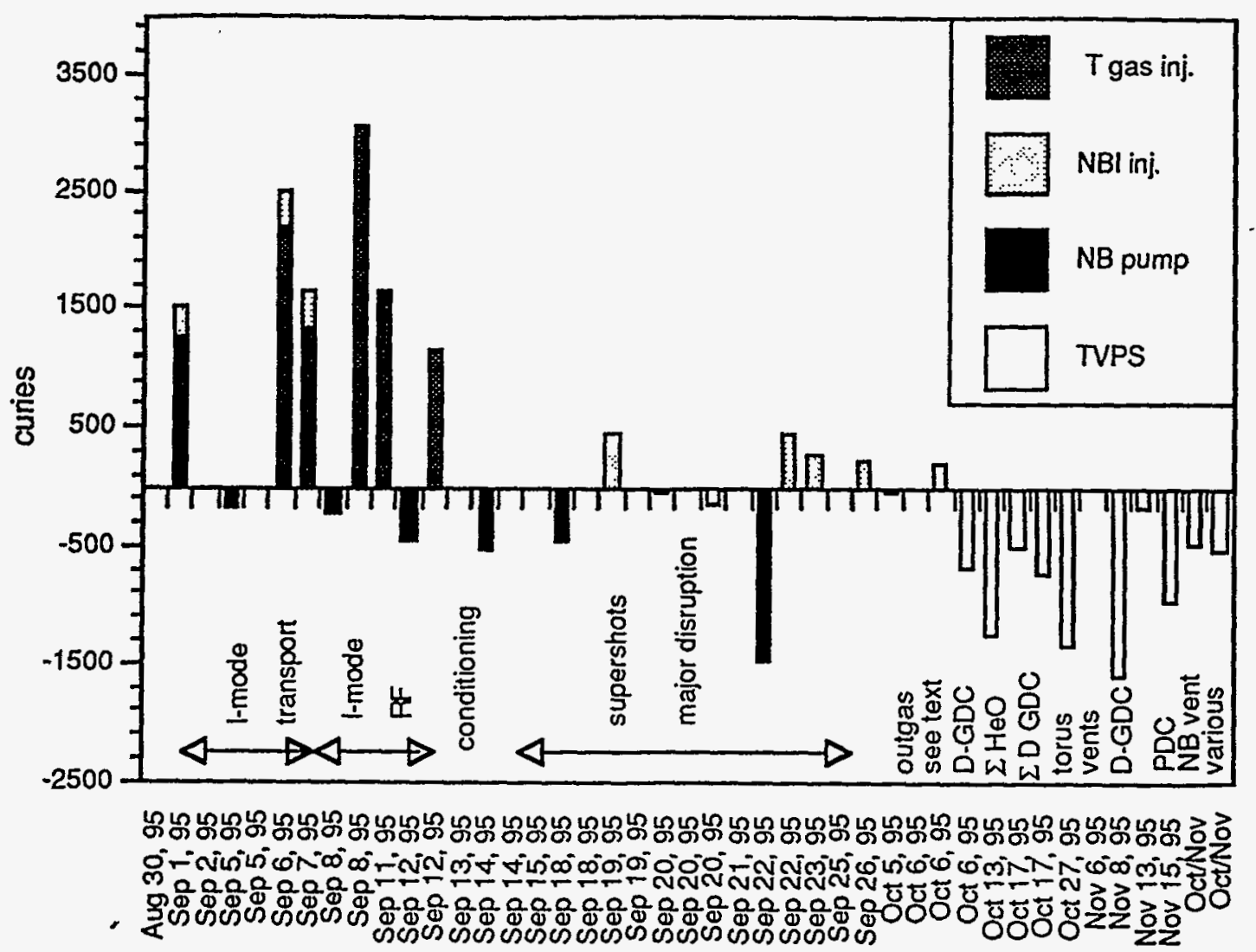

Fig. 2 History of tritium injected into the torus and measured exhaust during September/October 1995. GDC represents glow discharge cleaning. The symbols $\Sigma$ D-GDC, $\Sigma$ HeO GDC are the sum from several days -see fig. 3. In the legend 'TVPS' refers to the torus vacuum pumping system, 'NB pump' to tritium recovered from the neutral beam cryopanels , 'NB inj.' is tritium injected via the neutral beams (including cold gas), and ' $T$ gas inj.' is tritium gas directly puffed into the torus

the neutral beam cryopanels and via the torus vacuum pumping system. A running total of the cumulative input and exhaust, the in-vessel inventory and the fractional retention is calculated in the remaining columns. The fractional retention is defined as ratio of the cumulative tritium injected into TFTR during September-November 1995, less the cumulative exhaust; divided by the cumulative tritium injected. Note that the release of tritium is continuous but it was measured periodically, i.e. a 'NB pump' entry reflects tritium accumulated since the previous cryopanel regeneration.

On 30th August 1995 the value of in-vessel inventory, given by the tritium accounting system, stood at $6,863 \mathrm{Ci}$. Over the next 12 days $10,600 \mathrm{Ci}$ were injected by tritium gas puff and $900 \mathrm{Ci}$ by neutral beam injection while an estimated $860 \mathrm{Ci}$ were recovered indicating a short term retention above $90 \%$. It should be noted that no attempts were made to remove tritium in this period, on the contrary, the aim was to increase the tritium concentration in the plasma as much as possible. A 50 minute duration helium glow discharge, used to speed recovery from a 
disruption, yielded negligible ( $<20 \mathrm{Ci})$ tritium exhaust. The following period of plasma operation, from 12th-18th September 1995, was aimed at restoring the limiter to a low recycling state by ohmic and neutral beam conditioning. Carbon blooms ${ }^{24}$ were encountered when the neutral beam power was raised, however, over time the threshold for blooms increased. Although no further tritium was injected into the plasma either directly or by neutral beams, the tritium content of the plasma remained high for several days in this period. Tritium continued to be present in the exhaust and an estimated $970 \mathrm{Ci}$ was collected. In the period 19th-26th September an additional 1,370 $\mathrm{Ci}$ was injected via the neutral beams, however no further tritium gas puffing was used. On 22nd September an unplanned 1.2 MA disruption occurred. Subsequent measurements of the tritium recovered by the neutral beam cryopanels yielded an unusually high value of $1,500 \mathrm{Ci}$, most of which was presumably released during the disruption. For the days 22-26 September all of the neutral beams (including the reserved beamline) used tritium, and the tritium exhaust from the torus could not be included in the above analysis (it is, of course, included in the global tritium accounting system described in section 3). Overall, from 1st September until the end of the run period on 26th September, a total of $12,900 \mathrm{Ci}$ was injected by gas puff and NBI and $3500 \mathrm{Ci}$ recovered, a retention fraction of $73 \%$. Summing the various tritium transfers cited above yielded an in-vessel inventory of $16,243 \mathrm{Ci}$. This was consistent with the global measurements of the in-vessel inventory of $16,440 \mathrm{Ci}$ and a nominal adjustment of $197 \mathrm{Ci}$ was added (row: 6 October 1995 in Table $\mathrm{l}$ ) to reconcile the difference.

\section{Tritium removal.}

There was no activity over the next 8 days, outgassing of the torus yielded only $36 \mathrm{Ci}$. Results from JET had indicated that a deuterium 'soak' was effective in removing tritium from the torus that was maintained at $300^{\circ}$ (Ref. 6). There was interest in measuring the efficacy of this technique for the ambient temperature TFTR limiter. Deuterium was added with the pump valves closed and the torus pressure was raised to $70 \mathrm{mtorr}$ for one hour. However negligible tritium was recovered $(5 \mathrm{Ci} \pm 9 \mathrm{Ci})$ indicating that this technique was ineffective in TFTR. Next a glow discharge sequence was undertaken and the results are shown in Fig. 3. The first deuterium glow discharge (D-GDC) removed $687 \mathrm{Ci}$ over 4 hours, an average rate of $172 \mathrm{Ci} /$ hour. The tritium content of the gas holding tank was continuously monitored over this period and indicated an initial removal rate of approximately twice this value, declining by a factor 4 over the 4 hours. The following glow discharge used $90 \%$ helium and $10 \%$ oxygen and removed $\approx 50 \mathrm{Ci} /$ hour. This rate did not decline. To obtain more information about the time dependence of the D-GDC removal rate, the next D-GDC was performed in two steps. The initial D-GDC removal rate was higher than at the end of the previous D-GDC. Continued D-GDC, after the vessel vent (see below) and bakeout, showed a removal rate declining to $10 \mathrm{Ci} /$ hour. 


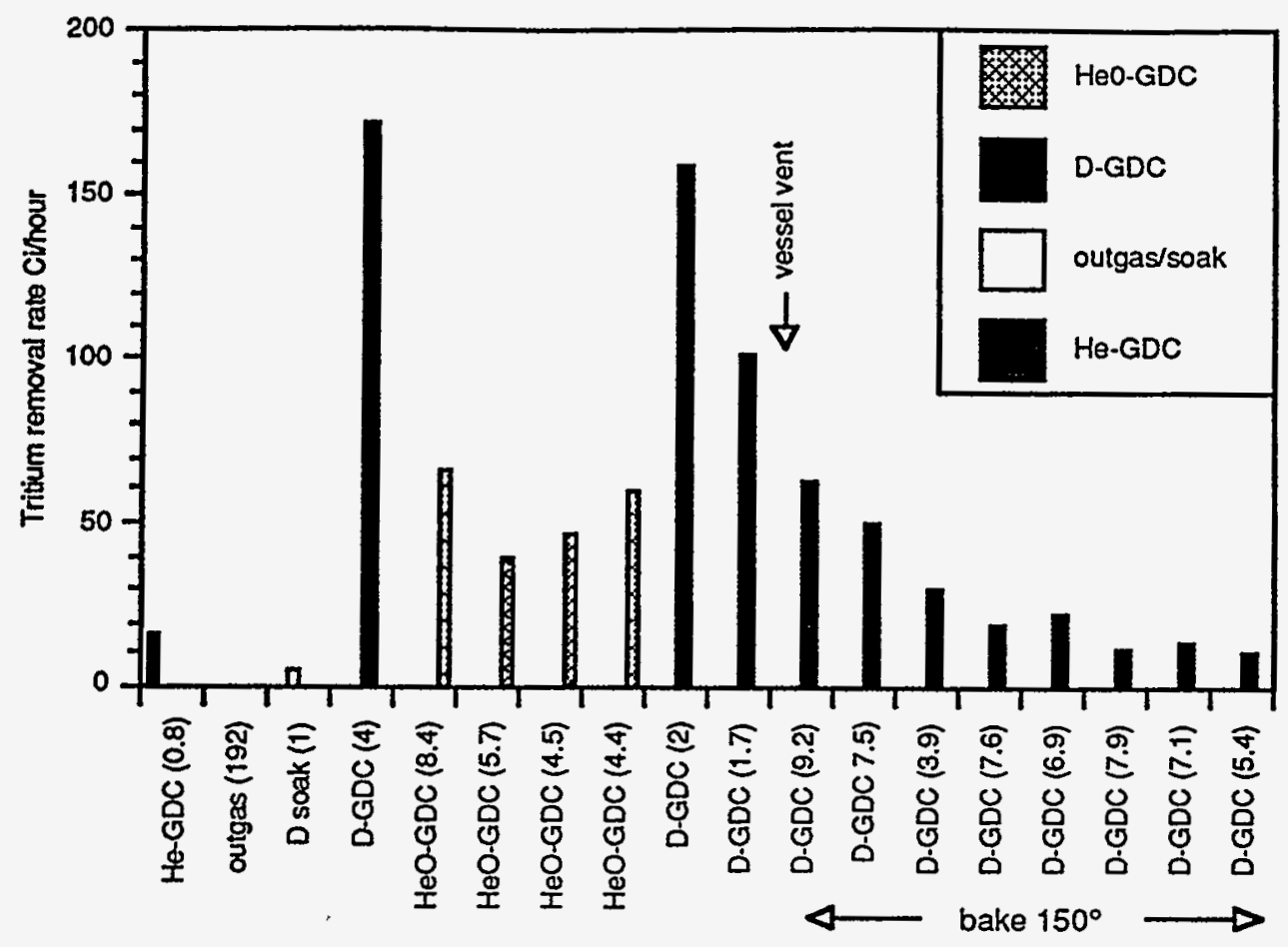

Fig 3. Tritium removal rate during outgassing, $\mathrm{D}$ soak and $\mathrm{He}-, \mathrm{D}-$, and $\mathrm{HeO}$ glow discharges. The data are arranged in chronological order. The duration in hours is given in parentheses.

Plasma ions in a glow discharge will interact with the limiter to a depth given by the range of the plasma ions in graphite, typically $1-10 \mathrm{~nm}$. Since tritium is buried by codeposition to a greater depth than this, deuterium or helium glow discharges were not expected to be effective in removing subsurface tritium. On the other hand a helium-oxygen glow is not limited in this way since it chemically reacts with the graphite and removes it in the form of carbon monoxide and carbon dioxide. The higher D-GDC tritium removal rate after the HeO-GDC illustrates that a fresh surface was uncovered.

An important consideration is the fraction of the in-vessel tritium inventory that would be released in the event of a credible vacuum accident. To determine this, room air was admitted to the torus in two steps: first, 18 torr of room air plus 20 torr of nitrogen was introduced into the torus and purged to the gas holding tank as a benchmark of releasable tritium; $745 \mathrm{Ci}$ were recovered. Secondly, room air was admitted to raise the torus pressure to near atmospheric (718 torr) and then purged, resulting in an additional 1,341 $\mathrm{Ci}$. This two step process resulted in 2,086 $\mathrm{Ci}$ of released tritium, approximately $15 \%$ of the in-vessel inventory. After this sequence 20 torr of room air was introduced and purged from the torus again to gauge the effectiveness of the vent in removing releasable tritium (as compared to the initial 18 torr effect). Only $15 \mathrm{Ci}$ were released, compared to the $745 \mathrm{Ci}$ obtained for the earlier 18 torr case, demonstrating that $85 \%$ of the initial in-vessel inventory was tenaciously held. 


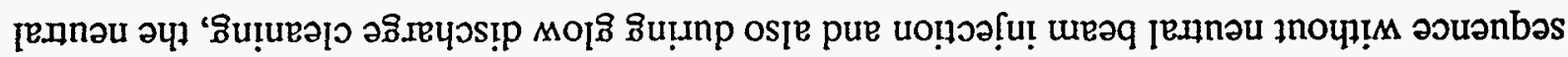

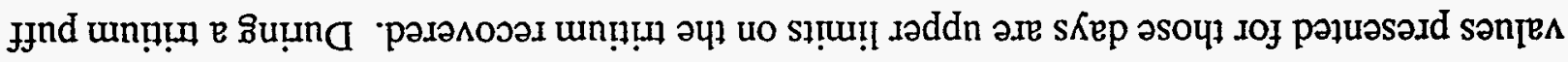

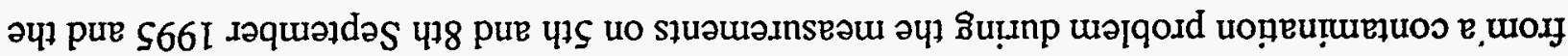

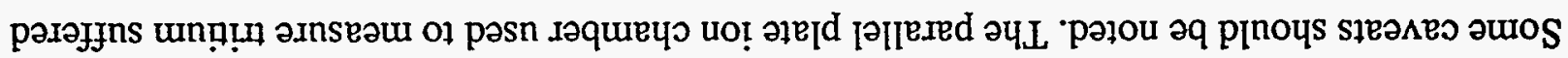

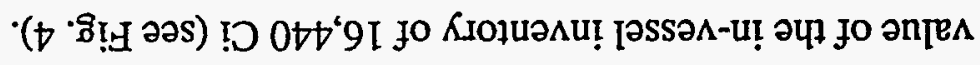

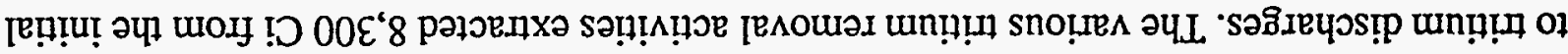

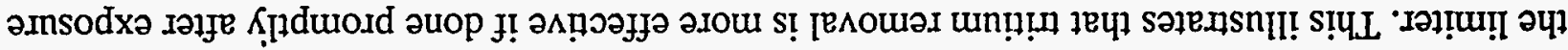

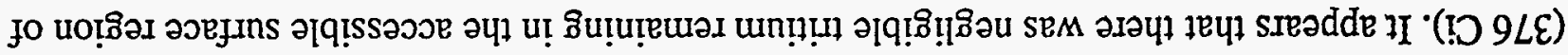

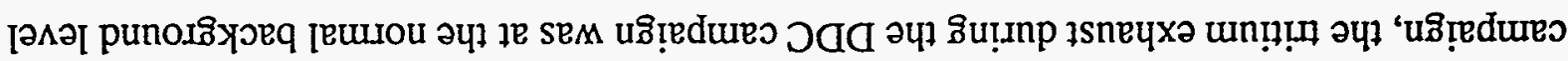

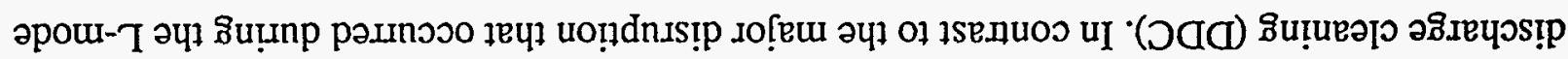

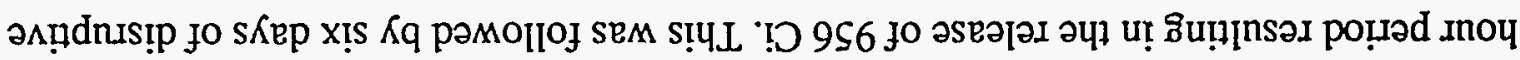

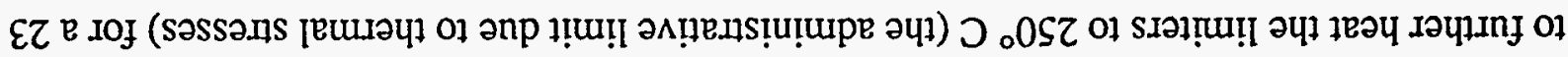

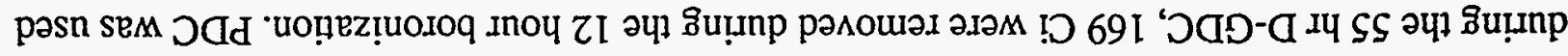

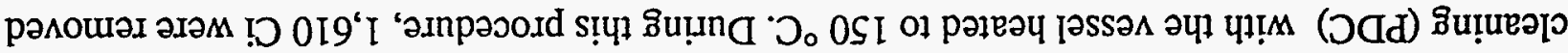

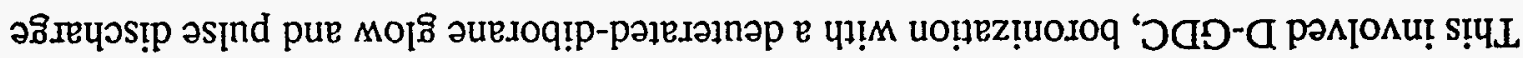

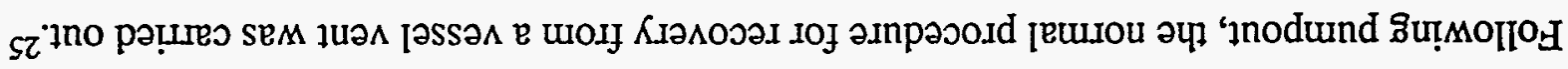

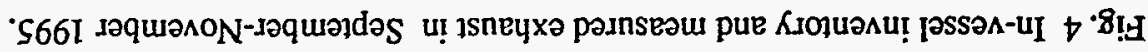

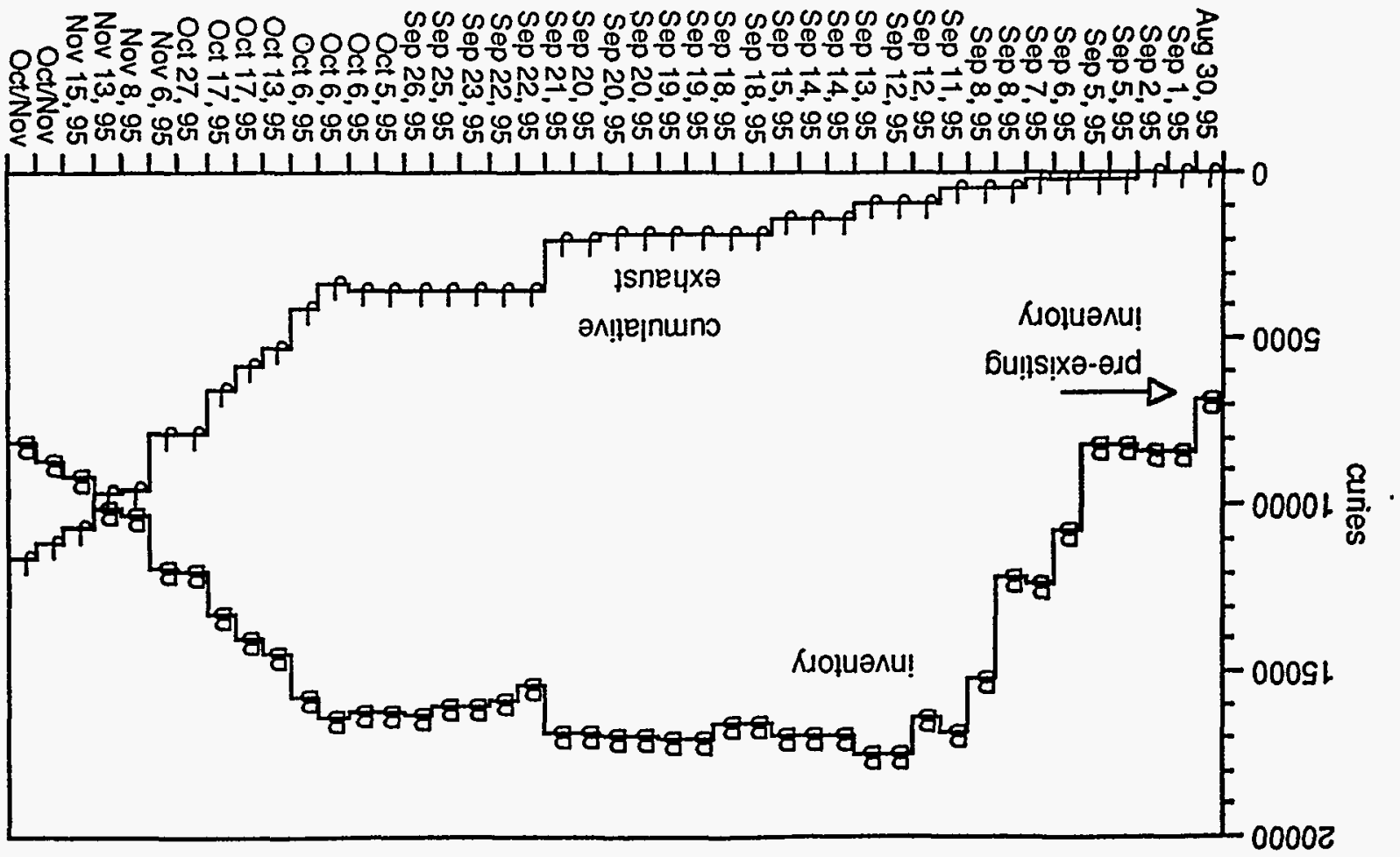




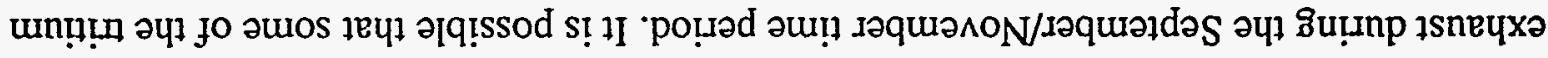

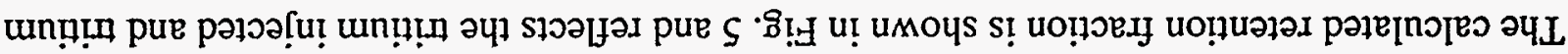

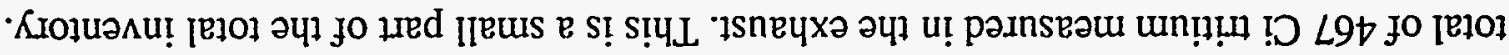
e pue хүй

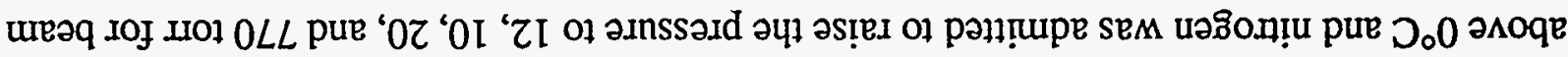

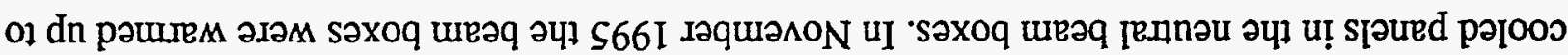

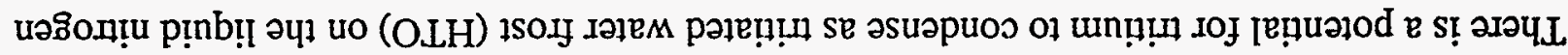

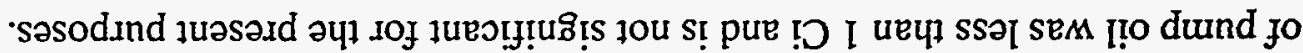

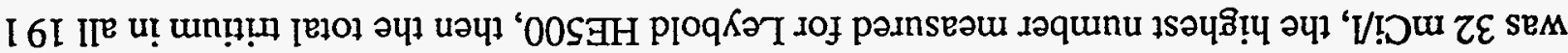

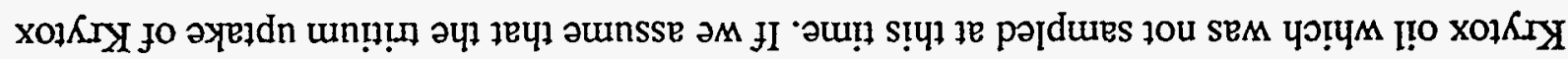

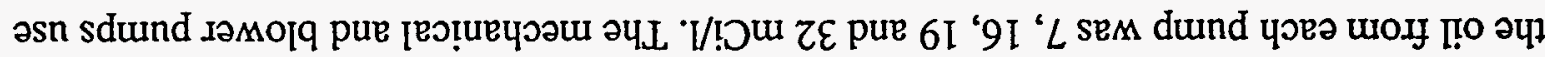

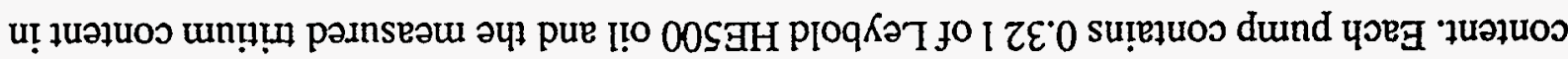

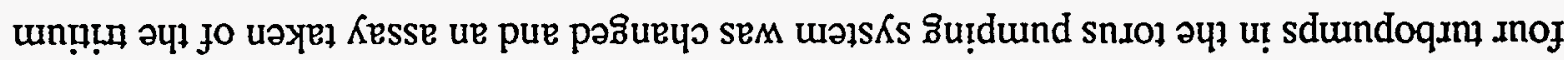

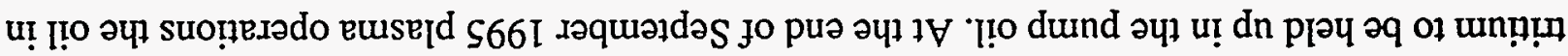

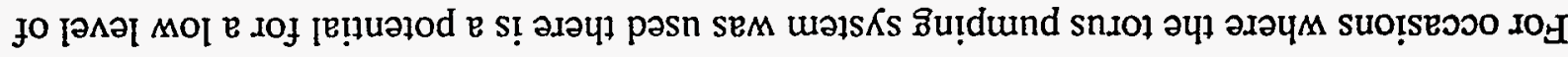

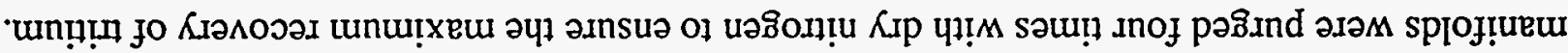

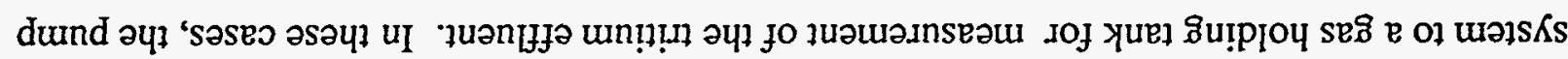

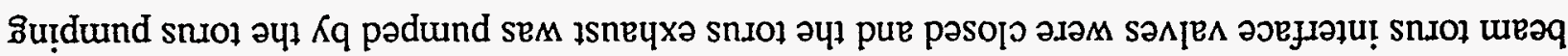

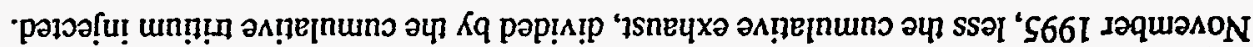

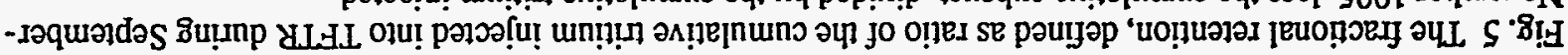

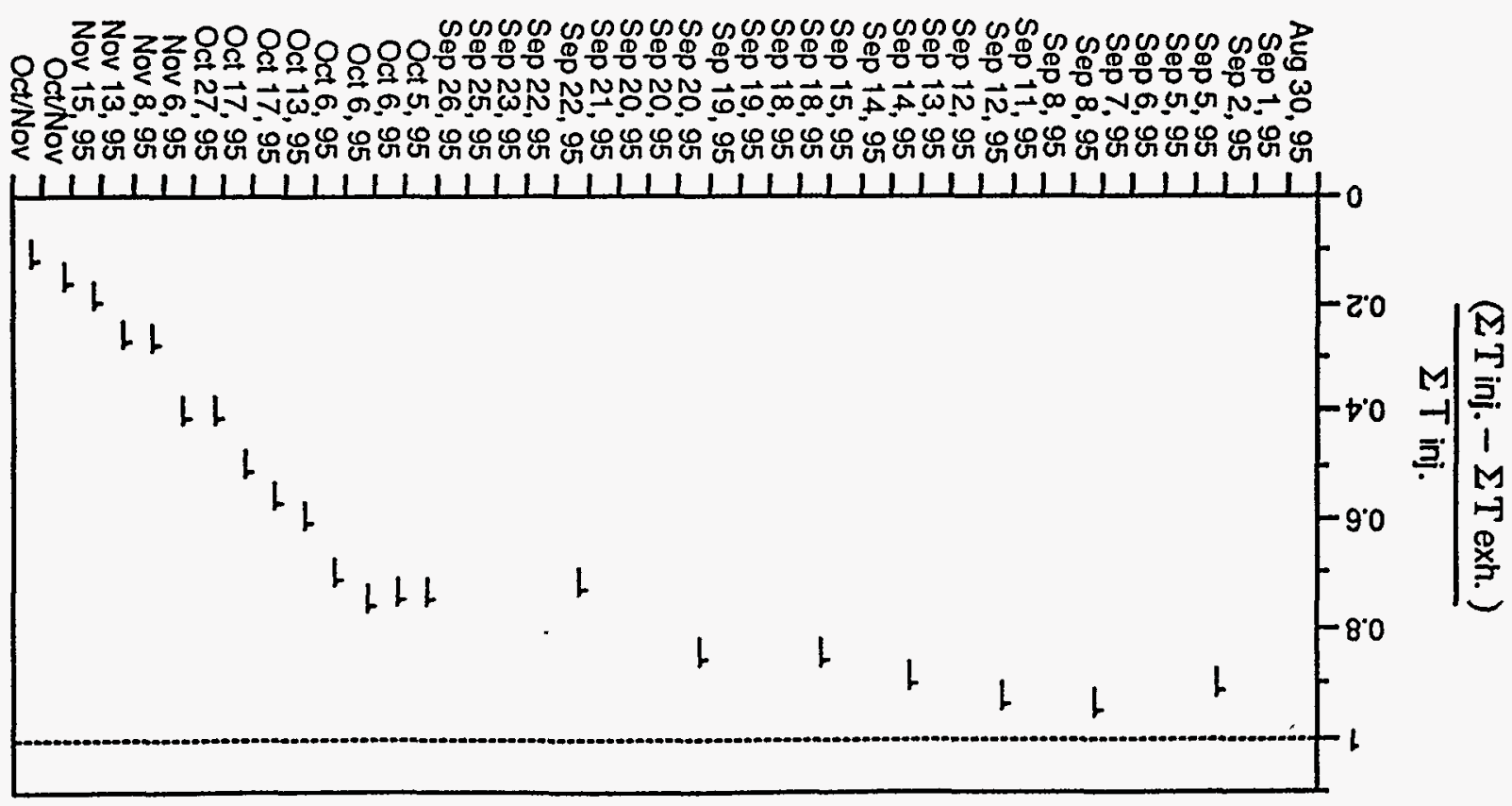


exhaust was injected into the torus at an earlier date, however the amount of tritium injected and the amount of tritium released from the limiter during a discharge both increased dramatically in this time period. The prior in-vessel inventory is believed to be buried by co-deposition and not to significantly contribute to the exhaust.

\section{Summary}

The aim of the tritium gas injection in the L-mode campaign in early September 1995 was to maximize the tritium in the plasma. In this period no attempt was made to remove tritium and the retention of injected tritium was high $(>90 \%)$. After the campaign there was a sequence of conditioning discharges including deuterium neutral beam heated discharges which restored the limiter to a low recycling state followed by a successful campaign to reduce the tritium in-vessel inventory. The amount of tritium released depends both on the efficacy of a particular technique and the quantity of tritium that is accessible. This is illustrated by the conspicuous increase in tritium recovered from the cryopanels in the regeneration immediately following a major disruption on September 20,1995 while the final disruptive discharge cleaning campaign released negligible tritium. Also noteworthy was the initial high removal rate of deuterium glow discharges. Exposing the torus to 718 torr of room air resulted in a release of approximately $2,100 \mathrm{Ci}$, a small fraction of the in-vessel inventory. The various tritium removal activities were successful in removing half of the in-vessel inventory. In the period 18 November 1995 2 January 1996 a further $987 \mathrm{Ci}$ were recovered. While various conditioning activities (PDC, DDC, He-GDC, boronization) were undertaken in this period the removal rate per day was low and is considered to be at a background level.

For inventory purposes it is proposed to treat part of the in-vessel inventory as 'tenaciously held' and unlikely to be released in the event of a credible vacuum accident. The most conservative approach would be to assume that the release could not exceed that observed for the torus vent prior to the bakeout and conditioning (which further depleted the tritium). Of the $7,163 \mathrm{Ci}$ remaining tritium in the in-vessel inventory on 2 January 1996, 5,000 $\mathrm{Ci}$ is considered to be tenaciously held and it is proposed that this be accounted for separately. The level of potentially releasable tritium is much less than the $20,000 \mathrm{Ci}$ administrative limit and is not a constraint on operations.

Comparing TFTR and JET, deuterium glow conditioning and the major disruption were found to be effective in removing tritium in both machines. A significant difference was that the tritium release rate with a deuterium 'soak' was negligible in TFTR while high in JET. This difference 
may be related to the mobility of hydrogen isotopes in graphite at the different temperatures (ambient in TFTR and $300^{\circ} \mathrm{C}$ in JET).

Since 9 December 1993 there have been 4257 high power (>10 MW NBI) discharges in TFTR, 402 of which have involved tritium beam injection. Tritium usage is expected to be higher in future DT machines and active control of the tritium inventory essential to avoid build up of tritium inventory. Deuterium glow discharges appear to be an interesting option for limiting the tritium inventory. Tritium injected during a day's plasma operations will be localized close to the surface of the graphite. At the initial rate of tritium removal by D-GDC in TFTR, a one hour glow discharge removes $170 \mathrm{Ci}$ of tritium. This matches the tritium injected by a cumulative 46 MW-sec of tritium neutral beams injection and corresponds to 2-8 discharges depending on the beam power and D/T mix used. In practice the D-GDC may need to be followed by conditioning to restore the limiter to a low recycling state.

Table II. Summary of efficacy of removal techniques in TFTR.

\begin{tabular}{|c|c|}
\hline Machine operation: & Comments: \\
\hline He-GDC, outgas, D soak & Ineffective \\
\hline D-GDC & $\begin{array}{l}\text { Initial removal rate high ( }>170 \mathrm{Ci} / \text { hour), declining to } 10 \mathrm{Ci} / \text { hour. } \\
\text { Accesses only tritium on surfaces exposed to discharge. }\end{array}$ \\
\hline $\mathrm{HeO}-\mathrm{GDC}$ & Rate $\approx 50 \mathrm{Ci} /$ hour - constant with time \\
\hline 718 torr room air & $2,086 \mathrm{Ci}$ removed, access to all surfaces \\
\hline Disruptions & $\begin{array}{l}\text { Flash heating of limiter surface near midplane. } \\
\text { Release of recently retained tritium. }\end{array}$ \\
\hline PDC & Heats limiter to $250^{\circ}$ C. $956 \mathrm{Ci}$ removed over 23 hours. \\
\hline Boronization & $\begin{array}{l}\text { Little tritium released, most near surface tritium already } \\
\text { removed. }\end{array}$ \\
\hline
\end{tabular}

\section{Acknowledgments.}

We would like to acknowledge contributions from D Mansfield, C K Phillips, J Strachan, and $\mathrm{G}$ Taylor. This work was supported by the US Department of Energy Contract No. DE-AC02$76 \mathrm{CH03073.}$ 
Table I. History of tritium injected into the torus and measured exhaust during September - November 1995. The abbreviations are explained in section 4 and the units are curies. The data in italics represents an upper limit. The experimental uncertainty is $\pm 2 \%$ for tritium injection and $\pm 5 \%- \pm 7 \%$ for pumping, however, numbers are given to the nearest curie to avoid rounding errors in the summations.

\begin{tabular}{|c|c|c|c|c|c|c|c|c|c|}
\hline Date & Plasma Ops. & T puff & NB inj. & $\begin{array}{c}\mathrm{NB} \\
\text { pump }\end{array}$ & $\begin{array}{l}\text { turbo } \\
\text { pump }\end{array}$ & $\begin{array}{l}\text { Sum } \\
\text { input }\end{array}$ & $\begin{array}{l}\text { Sum } \\
\text { output }\end{array}$ & Inventory & $\begin{array}{c}\% \\
\text { retention }\end{array}$ \\
\hline 30-Aug & inventory & & & & & 0 & 0 & 6,863 & \\
\hline 1-Sep & DT L-mode & 1244 & 276 & & & 1,520 & 0 & 8,383 & \\
\hline 2-Sep & & & & & -10 & 1,520 & 10 & 8,374 & \\
\hline 5-Sep & & & & -156 & & 1,520 & 166 & 8,218 & $89 \%$ \\
\hline 5-Sep & D L-mode & & & & & 1,520 & 166 & 8,218 & \\
\hline 6-Sep & $\begin{array}{l}\text { D L-mode } \\
+ \text { He4 GDC }\end{array}$ & 2193 & 304 & & -13 & 4,018 & 179 & 10,702 & \\
\hline 7-Sep & DT L-mode & 1319 & 314 & & & 5,650 & 179 & 12,335 & \\
\hline 8-Sep & & & & -228 & & 5,650 & 407 & 12,107 & $93 \%$ \\
\hline 8-Sep & $\mathrm{FF}$ & 3056 & & & & 8,707 & 407 & 15,163 & \\
\hline 11-Sep & F & 1630 & & & & 10,337 & 407 & 16,793 & \\
\hline 12-Sep & & & & -453 & & 10,337 & 860 & 16,340 & $92 \%$ \\
\hline 12-Sep & RF then condit. & 1163 & & & & 11,499 & 860 & 17,502 & \\
\hline 13-Sep & condit. & & & & & 11,499 & 860 & 17,502 & \\
\hline 14-Sep & & & & -534 & & 11,499 & 1,394 & 16,968 & $88 \%$ \\
\hline 14-Sep & condit. & & & & & 11,499 & 1,394 & 16,968 & \\
\hline 15-Sep & D supershot & & & & & 11,499 & 1,394 & 16,968 & \\
\hline $\begin{array}{l}\text { 18-Sep } \\
\text { 18-Sep }\end{array}$ & D supershot & & & -439 & & $\begin{array}{l}11,499 \\
11,499\end{array}$ & $\begin{array}{l}1,833 \\
1,833\end{array}$ & $\begin{array}{l}16,529 \\
16,529\end{array}$ & $84 \%$ \\
\hline 19-Sep & & & 447 & & & 11,946 & 1,833 & 16,976 & \\
\hline 19-Sep & DT supershot & & & & & 11,946 & 1,833 & 16,976 & \\
\hline 20-Sep & & & & -36 & & 11,946 & 1,869 & 16,940 & $84 \%$ \\
\hline 20-Sep & D supershot & & & & & 11,946 & 1,869 & 16,940 & \\
\hline 20-Sep & disruption & & & & -139 & 11,946 & 2,008 & 16,801 & \\
\hline 21-Sep & D supershot & & & & & 11,946 & 2,008 & 16,801 & \\
\hline 22-Sep & & & & -1483 & & 11,946 & 3,490 & 15,319 & $71 \%$ \\
\hline 22-Sep & DT supershot & & 448 & & & 12,394 & 3,490 & 15,767 & \\
\hline 23.Sep & DT supershot & & 266 & & & 12,660 & 3,490 & 16,033 & \\
\hline 25-Sep & D supershot & & & & & 12,660 & 3,490 & 16,033 & \\
\hline 26-Sep & DT supershot & & 210 & & & 12,871 & 3,490 & 16,243 & \\
\hline 5-Oct & outgas & & & -36 & & 12,871 & 3,526 & 16,208 & $73 \%$ \\
\hline 6.Oct & D soak & & & & -5 & 12,871 & 3,532 & 16,202 & $73 \%$ \\
\hline $6-0$ ct & see sect. 4 & & & & 197 & 12,871 & 3,335 & 16,399 & $74 \%$ \\
\hline 6-Oct & $D-G D C$ & & & & -687 & 12,871 & 4,021 & 15,713 & $69 \%$ \\
\hline 13-Oct & $\mathrm{HeO-GDC}$ & & & & -1249 & 12,871 & 5,270 & 14,463 & $59 \%$ \\
\hline 17-Oct & $D G D C$ & & & & -495 & 12,871 & 5,766 & 13,968 & $55 \%$ \\
\hline 17-Oat & vent 38 torr & & & & -745 & 12,871 & 6,511 & 13,223 & $49 \%$ \\
\hline 27-Oct & vent 720 torr & & & & -1341 & 12,871 & 7,852 & 11,882 & $39 \%$ \\
\hline 6-Nov & vent 20 torr & & & & -15 & 12,871 & 7,867 & 11.867 & $39 \%$ \\
\hline 8-Nov & $\begin{array}{r}\text { bake } 150^{\circ} \mathrm{C} \\
+D-G D C\end{array}$ & & & & -1609 & 12,871 & 9,476 & 10,258 & $26 \%$ \\
\hline 13-Nov & Boronization & & & & -169 & 12,871 & 9,645 & 10,089 & $25 \%$ \\
\hline 15-Nov & PDC & & & & -956 & 12,871 & 10,601 & 9,133 & $18 \%$ \\
\hline OctNov & NB vent & & & & -467 & 12,871 & 11,068 & 8,666 & $14 \%$ \\
\hline Oct/Nov & various & & & & .524 & 12,871 & 11,592 & 8,141 & $10 \%$ \\
\hline
\end{tabular}




\section{References:}

1 R A Causey, M I Baskes, and K L Wilson, J. Vac. Sci.Technol. A4 ,1189 (1986).

2 R A Causey, J. Nucl. Mater. 162-164, 151 (1989).

3 A A Haasz, P Franzen, J W Davis, S Chiu and C S Pitcher, J. Appl. Phys. 77, 66 (1995).

4 'Tritium retention on TFTR', H F Dylla and K L Wilson Ed., Princeton University, Plasma Physics Laboratory Report PPPL-2523 (April 1988) 108 pp.

5 'Tritium retention and conditioning of graphite limiters in TFTR', M Ulrickson et al., Nucl. Fus. Suppl, 1989 Vol III, IAEA-CN-50/G-III-1 P419-427; and 'Deuterium (tritium) retention in TFTR', M Ulrickson, presented at the IAEA Three Large Tokomak Workshop on Tritium Experiments, May 19-20, 1992.

6 P Andrew et al. Nucl. Fusion 33, 1389 (1993).

7 J P Coad, J.Nucl. Mater. 226, 156 (1995).

8 K M McGuire et al., Phys. of Plasmas 2, 2176-2188 (1995).

9 B E Mills, D A Buchenauer and A E Pontau and M Ulrickson, J. Nucl. Mater. 162-164, 343349 (1989).

10 R T McGrath and J N Brooks, Nucl. Mater. 162-164, 350 (1989).

11 A Janos, E D Fredrickson, K M McGuire, Y Nagayama, D K Owens and E Wilfred, J. Nucl. Mater. 196-198, 602-606 (1992).

12. A T Ramsey, C E Bush, H F Dylla, D K Owens, C S Pitcher, M A Ulrickson Nucl. Fusion 31, 1811 (1991).

13 K H Berkner, R V Pyle, and J W Stearns, Nucl. Fusion 15, 249 (1975).

14 J H Kamperschroer, L R Grisham, L J Lagin, T E O'Connor, R A Newman, T N Stevenson, A von Halle, and K E Wright, Rev. Sci. Instrum. 66, 632 (1995).

15 P H LaMarche et al., Fusion Technol. 26, 427 (1994)

16 A Nagy et al. in preparation.

17 M Caorlin et al. "A tritium vessel clean-up experiment in TFTR" Europhysics Conference Abstracts, Ed. E Joffrin, P Platz and P E Stott, Vol. 18B part 1, 18-21 (1994).

18 Steve Scott et al. in preparation

19 C K Philips et al. in preparation.

20 C H Skinner, H Adler, R V Budny, J Kamperschroer, L C Johnson, A T Ramsey, D P Stotler, Nucl. Fusion 35, 143-151 (1995).

21 P C Efthimion, L C Johnson, C H Skinner, J Strachan, E Synakowski, M Zarnstorff, H Adler, C Barnes, R V Budny, J Kamperschroer, W W Lee, M Loughlin, D McCune, A T Ramsey, G Rewoldt, A L Roquemore, D P Stotler, W M Tang and the TFTR Group. 
Proceedings of the 15th International Atomic Energy Agency Conference on Plasma Physics and Controlled Nuclear Fusion Research 1994 (September 1994, Seville Spain) Vol. 1, 289305, IAEA Vienna, 1995.

22 J D Strachan, M Bell, A Janos, S Kaye, S Kilpatrick, D Manos, D Mansfield, D Mueller, $\mathrm{K}$ Owens, C S Pitcher, J Snipes, J Timberlake, J. Nucl. Mater. 196-198, 28 (1992)

23 D Mansfield et al., Phys. Plasmas 2, 4252-4256 (1995).

24 A T Ramsey, C E Bush, H F Dylla, D K Owens, C S Pitcher, M A Ulrickson, Nucl. Fusion 31, 1811 (1991).

25 D Mueller, P H LaMarche, M G Bell et al., J. Vac. Sci. Technol. A9, 2713 (1991).

\section{DISCLAIMER}

This report was prepared as an account of work sponsored by an agency of the United States Government. Neither the United States Government nor any agency thereof, nor any of their employees, makes any warranty, express or implied, or assumes any legal liability or responsibility for the accuracy, completeness, or usefulness of any information, apparatus, product, or process disclosed, or represents that its use would not infringe privately owned rights. Reference herein to any specific commercial product, process, or service by trade name, trademark, manufacturer, or otherwise does not necessarily constitute or imply its endorsement, recommendation, or favoring by the United States Government or any agency thereof. The views and opinions of authors expressed herein do not necessarily state or reflect those of the United States Government or any agency thereof. 